\title{
Osteopathic Manipulation Treatment on postural balance: a systematic review.
}

\author{
Carolina Fantinel Veloso', Aron Ferreira da Silveira², Michele Vargas Garcia ${ }^{3}$, Caio Alexandre Parra Romero ${ }^{4}$
}

\begin{abstract}
Introduction: The postural balance is achieved through the interaction between the visual, proprioceptive and vestibular systems. Osteopathic manipulation treatment may interact with these systems through neural or sensory facilitation and consequently, restore or optimize the postural balance. Objective: Find and analyze studies that evaluated the effects of osteopathic manipulation in the balance of individuals. Methods: systematic review using the health descriptors (DeCS) "osteopathic manipulation treatment" and "postural balance", posting articles between 2009 and 2015 in different countries, in SciELO, LILACS and PubMed databases, to respond to the objective of study. Results: it included six scientific articles, of different nationalities, who used various maneuvers osteopathic manipulation in the treatment of postural balance, measured by force platform ( 2 studies), baropodometry ( 2 studies), functional questionnaire DHI (1 item) and computerized dynamic posturography ( 1 article) Conclusion: The osteopathic manipulation is effective in the treatment of postural balance in all studies included in the review.
\end{abstract}

Keywords: osteopathic manipulation treatment, evaluation, postural balance, dizziness.

\section{INTRODUCTION}

Postural balance is achieved through the accumulation of sensory information, postural reactions, personal experiences (memory), muscular system and afferents of oculomotor, vestibular and somatosensory. ${ }^{(1)}$

The foot and ankle may be considered contributors to the proprioceptive postural system as they allow adjustments to the lower limbs by the fixed point of contact with a surface. ${ }^{(2)}$

The cervical spine may also cause or contribute to imbalances of the body. The intrinsic muscle spindles of the cervical spine are in touch with vestibular nuclei through tractus spinovestibularis and are important in maintaining balance. ${ }^{(3,4)}$ Therefore, poor posture, trauma, tension or any "dysfunction" which leads to impaired cervical spine biomechanics may affect balance.

The cranial manipulation also affect the vestibular system through the temporal bone structures housing the vestibular apparatus. ${ }^{(5)}$ In a French study, ${ }^{(6)}$ it was used cranial manipulation for the treatment of 92 patients with cranial-cervical symptoms caused by road accidents, and showed generally improved postural stability (less oscillation).
The biomechanical changes in the cervical spine, feet, ankles, or any body structure osteopathic dysfunction may be corrected by the therapeutic application of manual forces guided to the functional and physiological improvement of the somatic system. ${ }^{(7,8)}$

The osteopathic manipulation (OM) includes direct techniques (on the tissue or joint) in high-speed, low amplitude and muscle power, and also includes indirect techniques such as counterstrain and myofascial release (applied away from the tissue restriction). ${ }^{(9)}$

Randomized controlled trials have evaluated the success of osteopathic and chiropractic manipulations leading to recognized results and findings on various systems: immune ${ }^{(10)}$, musculoskeletal(11), nervous and vascular ${ }^{(12)}$ and other outcomes in children. ${ }^{(13)}$

Mainly, OM may influence the proprioceptive system, and through it, postural balance. ${ }^{(14-18)}$

Thus, this review aimed to find studies which used OM in order to improve or restore postural balance, and to evaluate the conditions and characteristics of each study. 


\section{METHOD}

Through the systematic review method, a survey was carried out in the PubMed, SciELO and LILACS databases to find scientific articles published between 2009 and 2015, in different nationalities, using the following descriptors in health sciences (DeCS) and their synonyms: Osteopathic manipulation and postural balance.

The studies which passed through the initial filter, which had these descriptors in the title, had their summaries read by two researchers, who agreed with the inclusion or exclusion of the articles, and later, the reading in full text.

Full-text articles, national and international, with experimental studies of $\mathrm{OM}$ in one or more groups of individuals were considered as inclusion criteria, in order to evaluate the effects which these techniques caused on the postural balance of these individuals, through some evaluation instrument. The exclusion criteria were: incomplete articles, abstracts, reviews, and those which contemplated the objective of this research. Thus, the initial screening revealed 973 articles, and after refining the research according to inclusion/exclusion criteria and crossing of DeCS, we chose to include six scientific articles. (Figure 1)

\section{RESULTS}

The six scientific articles included in this review are described according to the year of publication, authors, intervention and main results (Table 1). Regarding the study type, it was found: a simple case study, two pilot studies, two single-blind controlled studies, one with an intentional sample, and one prospective clinical trial.

Regarding to the sample, two studies from the same research group, one pilot and the other experimental, used patients with dizziness or vertigo for at least three months, another two with an elderly population (older than 65 years), one study was carried out in the female young academic population, and another two studies used of mixed gender sample, as the majority female.

Regarding the type of OM, one study exclusively used cranial osteopathy ${ }^{(19)}$ making use of the following operations: the fourth maneuver ventricle "CV4", "V-spread" frontal and parietal, atlanto-occipital decompression, myofascial techniques for cervical spine and venous circulatory techniques.

Two other studies have exclusively used the tarsocrural or tibiotarsal maneuver for the ankle joint, and three studies have used global techniques, including: muscle-energy, myofascial, high-speed, low-amplitude, counterstrain, ligament and cranial.

\section{DISCUSSION}

In studies in which there was handling of the ankle and foot ${ }^{(20,21)}$ the instrument used to balance evaluation was stabilometry, which consist in quantifying anteroposterior and mediolateral oscillation of the body, while the individual remains in a baropodometry platform. ${ }^{(22,23)}$ This technique is commonly used to investigate changes in foot stability after the application of any therapeutic procedure. ${ }^{(24)}$

The force platform was the assessment method in two articles $^{(19,25)}$ in which one of them was French and the other American. The force platform measures the oscillations through the foot pressure center (FPC) and also notifies the anteroposterior, mid-lateral imbalances, forming a type of equilateral triangle. The SMART Balance Master platform ${ }^{(26)}$ includes virtual reality, through virtual reality glasses at six moments (spatial orientations) on a moving surface.

The assessment of the balance may be performed in subjects without complaints, as well as those with complaints of dizziness ${ }^{(26)}$ and vertigo. ${ }^{(9)}$ In these studies with symptomatic patients, the $\mathrm{DHI}$ questionnaire was applied as an instrument to assess the quality of life on the physical, emotional and functional scales. In both, there was a significant improvement in the overall score and in the three OM scales, and in those in which all patients presented benign paroxysmal positional vertigo (BPPV), despite a mild exacerbation of vertigo, patients have a good response in tolerate the OM.

Treatment with OM was not restricted to a specific region of the body because there is no evidence which it demonstrates that somatic dysfunction of a specific region causes or is correlated with vertigo, which is also consistent with the theory of osteopathy, which attempts to solve structural imbalances and improve the overall function of the body. ${ }^{(9)}$

Keywords:
$\begin{gathered}\text { Total articles per database: } \\ \text { "Manipulação osteopática" } \\ \text { "Osteopathic manipulative treatment" }\end{gathered}$
$\begin{gathered}\text { "Equilíbrio postural" } \\ \text { "Postural balance" } \\ =\end{gathered}$
$\begin{gathered}\text { Total final:7 artigos } \\ \text { Incluídos: } 6 \text { artigos }\end{gathered}$

Figure 1 - Flowchart of the search in Pubmed, ScieLo and LILACS databases. 
Table 1: Results of articles found per year and author and results of each intervention.

\begin{tabular}{|c|c|c|c|}
\hline Year & Author & Intervention & Results \\
\hline 2015 & Pellerin et al. (25) & $\begin{array}{l}\text { Three sessions were performed in which posture and } \\
\text { balance were evaluated by force platform. It was worked: } \\
\text { the hip joint, iliac, coccyx, foot and right ankle, besides } \\
\text { the right psoas muscle and right diaphragm and piriform. }\end{array}$ & $\begin{array}{l}\text { The results indicate that OM decreased the pain of the } \\
\text { patient and length and speed of the displacement of } \\
\text { oscillation center in force platform. }\end{array}$ \\
\hline 2013 & Carvalho et al. ${ }^{(20)}$ & $\begin{array}{l}\text { A session was held for ankle dysfunction prior } \\
\text { to tibiotarsis. Evaluation was performed through } \\
\text { baropodometry and stabilometry. }\end{array}$ & $\begin{array}{l}\text { The OM group presented greater oscillation ( } \mathrm{X} \text { and } \mathrm{Y} \\
\text { axes), at all times, compared to the control group. In } \\
\text { the intragroup comparisons, the OM group presented a } \\
\text { significant increase of the } \mathrm{Y} \text {-axis, post-intervention, with } \\
\text { open eyes. }\end{array}$ \\
\hline 2013 & Fraix et al. ${ }^{(26)}$ & $\begin{array}{l}\text { Four osteopaths applied high velocity muscle energy, low } \\
\text { amplitude, counterstrain, myofascial release, ligament } \\
\text { release and cranial osteopathy techniques. }\end{array}$ & $\begin{array}{l}\text { The balance improved significantly after a week after OM } \\
(p<.001) \text {, and no difference in the week following OM. } \\
(P=.20) \text {. }\end{array}$ \\
\hline 2011 & Lopez et al..$^{(19)}$ & $\begin{array}{l}\text { Seven osteopathy techniques were performed during } 4 \\
\text { weeks. Patients were evaluated on a force platform. The } \\
\text { conditions were: opened eyes, closed eyes and modified } \\
\text { Romberg's test. }\end{array}$ & $\begin{array}{l}\text { The OM group significantly reduced the unbalance for } \\
\text { the opened-eyes test after } 4 \text { sessions }(p=0.001) \text {. }\end{array}$ \\
\hline 2010 & Fraix. ${ }^{(9)}$ & $\begin{array}{l}\text { Three OM techniques were chosen for somatic cervical, } \\
\text { thoracic and lumbar dysfunctions, including myofascial, } \\
\text { ligament and muscle energy techniques. Its effectiveness } \\
\text { was assessed by DHI (Diziness Handicap Inventory). }\end{array}$ & $\begin{array}{l}\text { Sixteen patients }(88.9 \%) \text { completed treatment with OM. } \\
\text { All subjects who participated in the study had a diagnosis } \\
\text { of BPPV. }\end{array}$ \\
\hline 2009 & Sendín et al. ${ }^{(21)}$ & $\begin{array}{l}\text { Talocrural osteopathic manipulation session was carried } \\
\text { out. Baropodometric and stabilometric evaluations were } \\
\text { performed pre- and five minutes post-intervention by a } \\
\text { blind evaluator for treatment allocation. }\end{array}$ & $\begin{array}{l}\text { The results indicated that the averages of } \mathrm{X} \text { and } \mathrm{Y} \\
\text { coordinates in relation to anterior and posterior or lateral } \\
\text { movements and velocities, did not show significant } \\
\text { differences. }\end{array}$ \\
\hline
\end{tabular}

OM: osteopathic manipulation; BPPV: benign paroxysmal positional vertigo.

The studies used one to four sessions of osteopathy, with one session immediately induced postural control changes and three consecutive sessions were more efficient than a single. ${ }^{(25)}$

The effects of osteopathic manipulation of body sway indicated that the frequency of body oscillations in the anteroposterior direction decreased, while medial-lateral oscillations remained unchanged, throughout the session osteopathy, showing changes in the frequency of oscillation body. ${ }^{(25)}$ The authors questioned whether the fact is due to a greater contribution of the vestibular system and/or a lower contribution of somatosensory inputs, or if the changes may result from other somatosensory information input to the central nervous system ${ }^{(28)}$ or from the modification of the emotional status of patient. . $^{(27,29)}$

Regarding the quality of the included articles, verified by PEDro scale, one of the articles was a case study ${ }^{(25)}$ and, therefore, it did not obey the evaluation of randomized criteria. Another study, although experimental, admitted its own deficiencies when it did not blind the evaluators neither randomized the patients, since it did not have a control group. Nevertheless, the study showed satisfactory results from a voluntary sample and followed the eligibility criteria. ${ }^{(26)}$

Regarding the quality of the pilot studies, one ${ }^{(19)}$ recruited patients voluntarily but not randomized them, distributing the first 20 enrolled in the OM group and others in the control group, in which, although it participated of the assessment inter-group, it received no intervention. The other study ${ }^{\left({ }^{9}\right)}$ was also not randomized, and there was no control group, when the subjects were assessed before and after intervention with $\mathrm{OM}$.

Two studies were rated on the PEDro scale, consider clinical trials, but in one of them, the sample was intentional (women only), non-randomized, but separated into groups according to the presence or absence of osteopathic dysfunction. ${ }^{(20)}$ Despite this, this study blinded by the evaluator, presented satisfactory inter-groups results evidenced through graphs. Other study, best rated on the scale, it is a randomized single blind clinical trial, in which the sample eligibility criteria are clear and satisfactory, the OM was carried out by only one therapist and results evaluated inter-group. ${ }^{(21)}$ Nevertheless, the authors have limited the size of the study: Reduced sample size (32 patients), the non-use of manual therapy in the control group, and the intra-subject variability of the stabilometry data.

The techniques in $\mathrm{OM}$ do not require obeying a protocol, and the most varied approaches have presented positive results regarding the proprioception and postural balance, even in healthy individuals, without complaints of dizziness.

\section{CONCLUSION}

The six articles included in this review evidenced positive OM results on postural balance, however only one of the studies was characterized as an original randomized trial, scoring above four items on the PEDro scale. The studies in osteopathy, and basically on the vestibular system should be 
expanded, since they are scarce, in an area where innumerable professionals may act, with associated techniques and treatments. The OM is a low-cost, low-risk treatment for patients, and may be easily implemented in clinics, and should be performed only by a skilled and specialized professional.

\section{AUTHOR'S CONTRIBUTIONS:}

CFV: This author was responsible for choosing the topic, searching in the databases and writing the article, as well as reviewing and submitting; AFS: That author collaborated in the article writing and review; MVG: That author contributed to the review of the article; CAPR: That author collaborated with writing the article, reviewing the articles according to the scale, and the final review.

\section{CONFLICT OF INTERESTS:}

None.

\section{AUTHOR DETAILS}

2. Veterinarian, Professor of Department of Morphology and in the Graduate Program in Disorders of Human Communication, Universidade Federal de Santa Maria (UFSM), Santa Maria (RS), Brazil.

3. Speech Therapist, Adjunct Professor, Department of Speech and Hearing Therapy, professor in the Graduate Program in Disorders of Human Communication, Universidade Federal de Santa Maria (UFSM), Santa Maria (RS), Brazil.

4. Physiotherapist, Coordinator of the Physiotherapy course, Professor in the Physiotherapy Postgraduate Program in Osteopathy, Centro Universitário Franciscano (UNIFRA), Santa Maria (RS), Brazil. Universidade Federal de Santa Maria (UFSM), Santa Maria (RS), Brazil.

\section{REFERENCES}

1. Miralles RC, Heras C. Introducción a la biomecánica clínica del aparato locomotor. In: Miralles R, Miralles I, editors. Biomecánica clínica de los tejidos y lar articulaciones del aparato locomotor. 2a ed. Barcelona: Masson; 2005;p.3-14.

2. Villeneuve P. Le pied humain organe de la posture orthostatique. Kinesither. Sci. 1990;294:47-51

3. Nitz A, Peck D. Comparison of muscle spindle concentrations in large and small human epaxial muscles acting in parallel combinations. Am. Surg. 1986;52:273-277.

4. Bolton P. The somatosensory system of the neck and its effects on the central nervous system. J. Manipulative Physiol. Ther. 1998;21:553-563.

5. Grab D, Dvořák J, Gilliar W. Cervicogenic vertigo and headache. In: Dvořák J, Dvořák V, Gilliar W, Schneider W, Spring H, Tritschler T. Musculoskeletal Manual Medicine: Diagnosis and Treatment. New York, NY: Thieme; 2006:p.226-231.

6. Caporossi R. Influence of the osteopathic cranial treatment on the human gravitational posture. In: King $\mathrm{HH}$, ed. Proceedings of International Research Conference: Osteopathy in Pediatrics at the Osteopathic Center for Children in San Diego, CA 2002. Indianapolis, IN: American Academy of Osteopathy; 2005:p.82-85.

7. Ward R. Foundations for Osteopathic Medicine. Philadelphia, PA: Lippincott Williams \& Wilkins; 2003

8. DiGiovanna E, Schiowitz S, Dowling D. An Osteopathic Approach to Diagnosis and Treatment, Philadelphia, PA: Lippincott Wiliams \& Wilkins; 2005.

9. Fraix M. Osteopathic Manipulative Treatment and Vertigo: A Pilot Study. PM\&R. 2010;2:612-618.

10. Hodge LM, Downey HF. Lymphatic pump treatment enhances the lymphatic and immune system. Exp. Biol. Med. 2010;236:1109-1115.
11. Posadzki P, Edzard E. Osteopathy for musculoskeletal pain patients: a systematic review of randomized controlled trials. Clin. Rheumatol. 2011;30:285-291.

12. Chaibi A, Tuchin PJ. Chiropractic spinal manipulative treatment of migraine headache of 40-year duration using Gonstead method: a case study. J. Chirop. Med. 2011;10:189-193.

13. Cerritelli F, Pizzolorusso G, Ciardelli F, La Mola E, Cozzolino V, Renzetti $C$, et al. Effect of osteopathic manipulative treatment on length of stay in a population of preterm infants: a randomized controlled trial. BMC Pediatr. 2013;13:65.

14. Rogers RG. The effects of spinal manipulation on cervical kinaesthesia in patients with chronic neck pain: a pilot study. J. Manipulative Physiol. Ther. 1997;20:80-85.

15. Davis D. Chronic pain-dysfunction in whiplash-associated disorders. J. Manipulative Physiol. Ther. 2001;24:44-51.

16. Sung PS, Kang YM, Picar JP. Effect of spinal manipulation duration on low threshold mechanoreceptors in lumbar paraspinal muscles. Spine. 2005;30:115-122.

17. Palmgren PJ, Sandström PJ, Lundqvist FJ, Heikkilä H. Improvement after chiropractic care in cervico-cephalic kinesthetic sensibility and subjective pain intensity in patients with non-traumatic chronic neck pain. J. Man. Physiol. Ther. 2006;29:100-106.

18. Haavik-Taylor H, Bernadette M. Cervical spine manipulation alters sensory-motor integration: a somato-sensory evoked potential study. Clin. Neurophysiol. 2007;118:391-402.

19. Lopez D, King HH. Knebl JA, Kosmopoulos V, Collins DR, Patterson RM. Effects of Comprehensive Osteopathic Manipulative Treatment on Balance in Elderly Patients: A Pilot Study. JAOA. 2011;111(6):382-388.

20. Carvalho AR, de Ré D, Lam D, Cunha DM, Sena IB, Bertolini GRF. Efeito imediato da manipulação osteopática tibiotársica no equilíbrio estático de mulheres jovens. Rev. Bras. Ciênc. Esp. 2013;35(2):455-467.

21. Sendín FA, de las Peñas CF, del Rey MS, Vallejo FJM. Immediate effects of bilateral manipulation of talocrural joints on standing stability in healthy subjects. Manual Therapy. 2009;11:75-80.

22. Gagey P, Weber B. Posturologia - regulação e distúrbios da posição ortostática. 2. ed. São Paulo: Manole, 2000.

23. Rubira APF, et al. Eficiência da estabilometria e baropodometria estática na avaliação do equilíbrio em pacientes vestibulopatas. Neurobiologia, 2010;73(2):57-64.

24. Leardini A, et al. Kinematic of the human ankle complex in passive flexion-a single degree of freedom system. J. Biomech. 1999;32(2):111-118.

25. Pellerin F, Papin-Richard E, Guiheneuc P, Niel S, Guihard G. Can osteopathic manipulative treatment modify the posture in elderly people? A singlecase study. J. Bodyw. Mov. Ther. 2015;19:380-388.

26. Fraix M, Gordon A, Graham V, Hurwitz E, Seffinger MA. Use of the SMART Balance Master to Quantify the Effects of Osteopathic Manipulative Treatment in Patients With Dizziness. J. Am. Osteopath. Assoc. 2013;113(5):395

27. Goto F, Kabeya M, Kushiro K, Ttsutsumi T, Hayashi K. Effect of anxiety on antero-posterior postural stability in patients with dizziness. Neurosci. Lett. 2011;487:204-206.

28. Qiu F, Cole MH, Davids KW, Hennig EM, Silburn PA, Netscher $\mathrm{H}$, et al. Enhanced somatosensory information decreases postural sway in older people. Gait Posture. 2012;35:630-635.

29. Hainaut JP, Caillet G, Lestienne FG, Bolmont B. The role of trait anxiety on static balance performance in control and anxiogenic situations. Gait Posture 2011; 33. 